\title{
EDUCAÇÃO CIENTÍFICA NA PERSPECTIVA BACHELARDIANA: Ensino \\ Enquanto Formação
}

\section{SCIENTIFIC EDUCATION IN BACHELARD'S PERSPECTIVE: TEACHING AS FORMATION}

José Ernane Carneiro Carvalho Filho ${ }^{1}$

\section{RESUMO}

A problemática do ensino-aprendizagem aparece na epistemologia bachelardiana com um enfoque próprio, ao defender que aprender é uma mudança na constituição psíquica do sujeito. Isto é, aprender é superar os obstáculos que se interpõem no processo de aquisição do conhecimento. Bachelard argumenta que para que haja aprendizagem é importante que o estudante rompa com os obstáculos que impedem a compreensão dos conceitos científicos. Desta forma, o objetivo central do ensino de ciências não deve ser a exposição de aulas para a aquisição de uma grande quantidade de conteúdos, mas a superação dos obstáculos que impedem a compreensão do pensar e fazer ciência, na atualidade.

PALAVRAS CHAVES: Formação, Obstáculo epistemológico e Perfil epistemológico.

\section{ABSTRACT}

The problem of teaching-learning process appears in Bachelard's epistemology with a vey peculiar focus, as he defends that learning is a change in the psychological constitution of the subject, i. e., learning is to overcome obstacles that are interposed in the process of knowledge acquisition. Bachelard argues that the student's rupture with the obstacles that bar the comprehension of scientific concepts is important to allow learning to happen. This way, the main objective of science teaching should not lie on expositive classes in order to let the students acquire a large amount of contents, but the overcome of the obstacles that bar the comprehension of science thinking and science making nowadays.

KEYWORDS: formation, epistemological obstacle and epistemological profile

\footnotetext{
${ }^{1}$ Faculdade Regional de Ribeira do Pombal (FARRP)-ernanefilho@bol.com.br
} 
A compreensão do processo de ensino-aprendizagem depende, basicamente, da leitura que fazemos do mesmo. Não há a maneira correta e acertada de entender o complexo mecanismo da aprendizagem do ser humano. Todas as tentativas realizadas nesse campo devem ser vistas como contribuições importantes, porque auxiliam na ampliação do conhecimento que temos sobre este fenômeno.

Normalmente, as teorias de aprendizagem se agrupam em três correntes principais: comportamentalista, cognitivista e humanista. Para os comportamentalistas, a aprendizagem se constitui na modificação dos comportamentos visados pelo processo educacional, ou seja, se houve mudança de comportamento, então ocorreu aprendizagem. Para a corrente cognitivista, a aprendizagem está relacionada com os processos mentais de como se dão as decisões, o armazenamento, a transformação das informações cognitivas, isto é, se preocupa em determinar como se dá o mecanismo de aprendizagem na mente da pessoa. Os humanistas, por sua vez, entendem que a aprendizagem envolve não só avanço intelectual, mas também o aspecto emocional, por conceberem que a pessoa é um todo e não apenas a sua cognição.

Neste sentido, a compreensão da interpretação bachelardiana do processo de aprendizagem é relevante, porque é tratada a partir do ponto de vista de um epistemólogo, que estuda continuamente os processo de elaboração da ciência e nos permite vislumbrar como seria o mecanismo de aprendizagem, numa leitura relacionada com a forma de construção da ciência, na atualidade. É uma maneira diversa de entender a aprendizagem, porque o enfoque fundamental de sua proposta está na mudança das estruturas internas que dificultam o acesso ao novo saber, visto que sua perspectiva envolve a idéia de formação do sujeito.

Esta proposta destaca que o aspecto essencial do processo educacional é a sua transformação. Segundo ele, educar é promover meios que facultem a oportunidade de superação da constituição interna do ser numa outra forma de compreender e entender o mundo. Isto porque

O sujeito só se manifesta através de um trabalho, de um trabalho complexo que constitui, de um lado, a retificação do saber apreendido anteriormente, a polêmica das idéias que antes pareciam sólidas, e, de outro lado, um trabalho no intuito de afastar as intuições primeiras do sujeito que de imediato se opõem no ato de pensar e que constituem obstáculos epistemológicos. (BARBOSA \& 
BULCÃO, 2004, p. 52-53).

Educar não é, então, descarregar uma massa de conteúdos sem nexo, mas promover caminhos que facultem, ao educando, a oportunidade de superar as suas limitações e os seus obstáculos na aquisição de um conhecimento cada vez mais avançado. Porquanto, o acúmulo de conteúdo não é garantia de aprendizagem, porque o estudante que domina uma grande quantidade de assuntos, de uma determinada ciência, pode não estar pensando de acordo com aquela área do saber e esse saber pode não ter promovido uma mudança na maneira de perceber o mundo.

Esta é a forma de entender o processo de ensino-aprendizagem, onde o foco principal é o desenvolvimento das capacidades dos estudantes, facultando-lhes os meios necessários ao entendimento da ciência atual e o seu mecanismo de criação.

Assim, o cerne da educação deste pensador se constitui na compreensão dos limites que se interpõem ao processo de aquisição do saber. Daí a necessidade de se compreender em que nível de compreensão da realidade se encontra o educando. Tendo em vista que

É o homem inteiro, com sua pesada carga de ancestralidade e de inconsciência, com toda a sua juventude confusa e contingente, que teria de ser levado em conta se quiséssemos medir os obstáculos que se opõem ao conhecimento objetivo, ao conhecimento tranqüilo. (BACHELARD, 2001, p. 258).

Se a formação escolar de uma pessoa se dá através da superação dos obstáculos ao conhecimento, e esses obstáculos se constituem em retardos e perturbações, que estão no interior da mente da pessoa e terminam impedindo o avanço do saber, para se conseguir efetivar um processo de ensino eficiente é imprescindível que o professor conheça os mecanismos internos de processamento do aprendizado, já que o conhecimento se dá quando há superação de obstáculos.

Esses obstáculos, a que Bachelard refere-se, estão na mente da pessoa. Para ele, a razão "é constituída por todos os componentes da vida psíquica, e, para o espírito científico, é necessário conhecer os valores inconscientes que, às vezes, criam obstáculos ao desenvolvimento do conhecimento" (BARBOSA, 1996, p. 90). O 
conhecimento desses obstáculos vai permitir ao professor fazer um diagnóstico mais eficaz do processo de ensino-aprendizagem e aplicar melhor as estratégias para alcançar um bom resultado. Por isso, é necessária uma psicanálise do conhecimento, para "perceber os obstáculos que impedem o desenvolvimento do conhecimento cientifico, ajudando-o a tomar consciência dos seus instintos e trabalhar contra eles" (BARBOSA, 1996, p. 92).

Superar os obstáculos ao conhecimento é fundamental para que ocorra o aprendizado. Esse rompimento tem que começar em relação ao real imediato. Para o senso comum, a realidade é aquilo que pode ser tocado, manejado; mas, para apreender o conhecimento científico atual é necessária a ruptura com essa realidade imediata e adentrar num mundo onde o real é uma construção e não se constitui num mundo dado.

Partindo desse pressuposto, "a ciência não se preocupa em descrever o mundo, mas em construí-lo" (BARBOSA, 1996, p. 74). Assim, o conhecimento não seria uma cópia fiel do mundo externo, e sim uma construção racional da mente humana, visto que conhecer não é o mesmo que perceber o que é a realidade, mas uma construção aproximada da mesma.

Essa maneira de tratar a apropriação do conhecimento encontra respaldo em algumas teorias cognitivistas, como a que procura entender os processos mentais a partir de modelos construídos pelas pessoas. Segundo esses teóricos, entre eles Marco Moreira, "representações internas, ou representações mentais, são maneiras de 're-presentar' internamente o mundo externo. As pessoas não captam o mundo exterior diretamente, elas constrõem representações mentais (quer dizer, internas) dele" (MOREIRA, 1996, p. 1). Isto é, o ser humano não tem acesso direto e definitivo ao mundo, mas acessa-o de forma indireta, ao construir modelos mentais que procuram explicar esse mundo.

$\mathrm{Na}$ perspectiva de Bachelard, para que o estudante consiga construir um modelo mental adequado do mundo é indispensável, ao adentrar uma aula de ciências, que rompa com os obstáculos pré-existentes que impedem a aquisição do conhecimento. A meta do professor não deve ser repetir indefinidamente a lição, mas em promover uma catarse psíquica no educando, para que ascenda a uma condição de aprendiz do conhecimento. Por isso a educação é um

Processo oscilatório de formação do sujeito e do objeto, um processo árduo e difícil que exige consciência e fundamentalmente trabalho, 
um trabalho penoso de negação do saber que acreditávamos sólido e verdadeiro e a negação do próprio sujeito, das ilusões e crenças que tínhamos arraigadas no nosso eu mais profundo. (BARBOSA \& BULCÃO, 2004, p. 57).

Para realizar este intento, a existência de um perfil epistemológico se faz necessário, para se determinar o grau de maturidade da pessoa a partir de um dado conceito científico, permitindo ao professor precisar os meios necessários para promover um eficiente processo de ensino, a partir do nível do estudante. Segundo Bachelard, a compreensão de um dado conceito científico passa por cinco fases distintas: animismo, realismo, positivismo, racionalismo, racionalismo complexo e racionalismo dialético (BACHELARD, 1972, p. 25). Isto significa que uma pessoa pode entender determinado conceito no aspecto anímico, já outra pode entendê-lo no aspecto racional. Assim,

Uma só filosofia é pois insuficiente para dar conta de um conhecimento preciso. Se então se quiser fazer, a diferentes espíritos, exatamente a mesma pergunta a propósito de um mesmo conhecimento, ver-se-á aumentar singularmente o pluralismo filosófico da noção. Se ao interrogar-se sinceramente acerca de uma noção tão precisa como a noção de massa um filósofo descobre em si cinco filosofias, quantas se obterão se se interrogarem várias filósofos a propósitos de várias noções! Mas todo este caos pode ordenar-se se considerarmos que uma só filosofia não pode explicar tudo e se quisermos dar uma ordem às filosofias. Por outras palavras, cada filosofia fornece apenas uma banda do espectro nocional, e é necessário agrupar todas as filosofias para termos o espectro nocional completo de um conhecimento particular. (BACHELARD, 1972, p. 66).

Desta forma, a

Distribuição das várias filosofias presentes para cada conceito constitui o perfil epistemológico, específico para cada indivíduo, em um determinado momento histórico e traduz o estágio de amadurecimento que cada conceito tem para um indivíduo em particular, podendo ser utilizado, por exemplo, para um trabalho de levantamento das concepções prévias dos estudantes. (LÔBO, 2002, 
p. 154).

A identificação desse perfil facilita o trabalho do educador em sala de aula, ao fornecer o estágio em que se encontram os estudantes e definir uma estratégia mais eficaz na tentativa de efetuar uma ruptura com essas concepções. Assim, o papel primeiro do professor, no ensino de um novo conceito científico, será identificar o perfil conceitual dos estudantes, ou seja, a sua concepção prévia, sobre o conceito a ser estudado, para facilitar o seu aprendizado.

É a partir do conceito bachelardiano de perfil epistemológico que Mortimer constrói a idéia de perfil conceitual. Segundo ele, o perfil conceitual seria uma

Estratégia para a aprendizagem de conceitos científicos, em especial, de conceitos químicos. Esta noção permite que cada conceito seja mostrado como uma evolução, embora com rupturas, ao longo do processo histórico de sua construção, em direção a uma maior complexidade (racionalidade), em relação à estrutura cognitiva do aprendiz. (LÔBO, 2002, p. 154).

A partir da identificação do perfil conceitual do aluno é possível, ao professor, determinar as melhores estratégias para alcançar um melhor aprendizado de ciências.

No entanto, a idéia de uma mudança conceitual não é totalmente bem vista, porque pode ocorrer que os estudantes não modifiquem as suas concepções sobre os fenômenos estudados. O que Mortimer propõe então é

A construção de novos conceitos ou sistemas conceituais explicativos, [que] requer uma crítica dos antigos, mas, não necessariamente, seu abandono, aceitando-se que os alunos precisam de muitos deles para lidar com o mundo em contextos diferentes das ciências. (SILVA, 2002, p. 120).

Assim, o correto, segundo Mortimer, seria o ensino dos conceitos científicos que seriam aplicados no universo da ciência, mas que não seriam utilizados pelos estudantes em seu cotidiano. Isso permitiria que os estudantes não abandonassem os conceitos científicos que são contra-intuitivos. Essas idéias de Mortimer podem ser um caminho na educação científica dos estudantes, por não exigir a mudança que os estudantes têm sobre a realidade que os cerca, segundo 
aqueles que não concordam com Bachelard.

Bachelard, no entanto, defende uma mudança na compreensão que as pessoas têm do mundo. Porque, na sua perspectiva de educação, só ocorre aprendizagem quando há superação dos obstáculos que a impedem, ou seja, não há meio termo na epistemologia bachelardiana para o processo de aquisição do saber: só se aprende quando se rompe com a realidade imediata e com as idéias cristalizadas que trazemos.

Isto porque a ciência atual não parte do real concreto, mas de construções teóricas que procuram explicar a realidade, visto que "a ciência do século $X X$ se caracteriza exatamente por essa ruptura com o conhecimento imediato" (BARBOSA, 1996, p. 72). Por isso, a ciência atual não parte do real imediato, mas de problematizações criadas sobre a realidade buscando, compreender as leis que regem os fenômenos, porque "a preocupação do cientista não é mais observar e tentar reproduzir o real. Ele trabalha no sentido de construir um modelo matemático que ordene o real” (BARBOSA, 1996, p. 74), pois a essência da ciência é a construção de modelos que expliquem o real.

Para alcançar essa abstração da ciência não é suficiente ensinar o novo saber, mas é importante que os professores levem os estudantes a romperem com o saber enraizado em suas mentes. Os educadores de ciências precisam libertar-se da velha idéia de que o ensino de ciências

Começa como uma aula, que é sempre possível reconstruir uma cultura falha pela repetição da lição, que se pode fazer entender uma demonstração repetindo-a ponto a ponto. Não levam em conta que o adolescente entra na aula de física com conhecimentos empíricos já constituídos: não se trata, portanto, de adquirir uma cultura experimental, mas sim de mudar de cultura experimental, de derrubar os obstáculos já sedimentados pela vida cotidiana. (BACHELARD, 2001, p. 23).

A habilidade do professor deve voltar-se para outro aspecto do impacto social em sala de aula: o conhecimento trazido pelos alunos do ambiente em que vivem. É fundamental que o mestre auxilie o educando a perceber que o saber que ele traz não é um conhecimento acabado e correto, e sim um saber que deve ser superado. 
A ruptura entre o conhecimento comum e o conhecimento científico parece-nos tão nítida que estes dois tipos de conhecimento não poderiam ter a mesma filosofia. O empirismo é a filosofia que convém ao conhecimento comum. O empirismo encontra aí as suas raízes, as suas provas, o seu desenvolvimento. Pelo contrário, o conhecimento científico é solidário do racionalismo e, quer se queira quer não, o racionalismo está ligado à ciência, o racionalismo conhece uma atividade dialética que impõe uma extensão constante dos métodos. (BACHELARD, 1990, p. 260).

Percebe-se que a produção do conhecimento científico atual produz uma ruptura com o conhecimento vulgar e o professor deve ensinar ciências, na perspectiva da ciência, destacando o modelo de formulação do saber e procurando desenvolver metodologias que levem os estudantes a desligarem-se dos conhecimentos que trouxeram para a sala de aula.

Essa estratégia de relegar os saberes anteriores dos estudantes é importante, porque facilita o ensino-aprendizagem de novos conceitos. Um exemplo claro desse fato é quando se trabalha o conceito do espectro eletromagnético e se menciona que a luz visível é apenas uma ínfima parte das emissões desse espectro. Ou seja, o que vemos não é tudo o que é irradiado pela natureza. O mesmo se dá quando se fala dos infra e ultra-sons, que são ouvidos por outros animais e que o ser humano não é capaz de perceber. Isso tudo demonstra que, para o estudante compreender essa nova realidade científica, tem de afastar-se da realidade imediata em que vive, já que o real imediato não é o cenário onde se dão os fenômenos científicos. E, normalmente, o real científico nega o real imediato. Daí o imperativo de se romper com essa face do mundo

Essa ruptura com o conhecimento imediato é a marca da ciência contemporânea e, portanto, deve ser efetivada em sala de aula, para que os estudantes compreendam como se dá a criação do saber científico e entendam que o real imediato não é instrutivo, mas um obstáculo a um conhecimento científico porque "a realidade é o objeto do conhecimento, não o seu ponto de origem" (BARBOSA, 1996, p. 149).

Um obstáculo que Bachelard destaca e que dificulta a obtenção do saber é a idéia de generalização. A generalização impede que o sujeito tenha a noção 
exata do fenômeno em estudo, porque engloba as conclusões sobre uma realidade a outras, não percebendo que há peculiaridades do real que não podem ser estendidas a outros fatos. Uma das características do mundo científico é a complexidade dos fenômenos. Não é possível estudá-los a partir de leis gerais, sem que se perca a riqueza do particular, do momentâneo. A crença numa "natureza homogênea, harmônica, tutelar apagou todas as singularidades, todas as contradições, todas as hostilidades da experiência" (BACHELARD, 2001, p. 103).

Bachelard explica que, em todas as aulas de ensino elementar, é muito comum afirmar que todos os corpos caem; no entanto, é preciso enfatizar que nem todos os corpos caem, já que os corpos arremessados a grandes alturas terminam entrando em órbita e não voltam à terra. Desta forma, fica evidente que não é possível fazer generalizações precipitadas, pois elas podem impedir o avanço do conhecimento científico.

Assim, é importante que o professor esteja atento, para evitar que os estudantes estabeleçam relações ou comparações entre fenômenos que não se correspondem e terminem aprendendo ciências de uma forma equivocada. $A$ generalização de um conhecimento através de uma lei só é possível depois de muita pesquisa e comprovação, através de exaustivas experiências, e isto precisa ficar muito evidente para os alunos.

Bachelard aponta outro obstáculo que dificulta 0 avanço do conhecimento. Este é o substancialismo que, segundo ele, "é um obstáculo para a cultura científica na medida em que impede, de certa maneira, o surgimento de matéria nova, ou seja, a produção de matérias" (BARBOSA, 1996, p. 103). Esta tese bachelardiana é significativa, porque esclarece as dificuldades que os estudantes têm em romper com a concepção oriunda dos sentidos. O substancialismo admite que o objeto possua características ocultas ou manifestas, não admitindo perceber as realidades essenciais do objeto, as leis matemáticas que regulam o fenômeno.

É a partir desta visão que se desenvolvem valores que atribuem qualidades especiais às substâncias. Um exemplo desse aspecto é as qualidades alquímicas que aparecem nas aulas de Química moderna e Bachelard menciona experiências vividas em sala de aula que comprovam a assertiva acima: "enquanto eu amassava o mercúrio que aumentava de volume, eu via o fascínio em seus olhos atentos. Diante desse interesse por tudo o que aumenta de volume, por tudo o que se amassa" (BACHELARD, 2001, p. 68). Nesse relato, vê-se, claramente, que os 
estudantes terminam atribuindo valores que o objeto não possui, em vez de procurarem as leis matemáticas que regem o fenômeno. Uma outra face que aparece na idéia de valorizar a matéria é a sexualidade. Ele afirma que o aspecto sexual está presente na mente do aluno contemporâneo.

É muito sintomático que uma reação química na qual entrem em jogo dois corpos diferentes seja imediatamente sexualizada, de modo às vezes um pouco atenuado, pela determinação de um dos corpos ser ativo e o outro passivo. No ensino da química, pude constatar que, na reação do acido com a base, quase todos os alunos atribuíam o papel de ativo ao ácido e o papel passivo à base. Num breve exame do inconsciente, logo se percebe que base é feminino e ácido, masculino. (BACHELARD, 2001, p. 243).

O professor deveria ensinar ciências com o intuito maior de defender o aluno dessas expectativas mágicas da matéria, para levá-los a entender a rede de relações que envolvem o fenômeno e possibilitem a sua compreensão no âmbito da ciência contemporânea.

Essa perspectiva racional da ciência deve ser enfatizada pelo professor, com metodologias e discursos que promovam a compreensão do modus operandi da ciência atual. Essas metodologias devem dar destaque especial aos processos teóricos que orientam a pesquisa científica, porque é o aspecto racional que direciona uma pesquisa e não o acaso, oriundo da observação. Este destaque dado à teoria pode ser feito com a realização de experiências que sejam orientadas pela teoria e que busquem comprovar sua formulação. Isto é muito importante, para que a concepção do estudante se forme neste ambiente, não num empirista. Trabalhando o ensino de ciências desta forma, permite-se que o estudante tenha uma real dimensão do papel da teoria no processo de aquisição do conhecimento, não sendo preciso que haja um discurso para explicar a predominância da teoria sobre a experiência, porque se o professor valorizar a experiência e falar da importância da teoria estará cometendo uma contradição que será percebida pelo aluno e este não acreditará em seu discurso.

Vê-se, portanto, que a ciência contemporânea não trabalha com a simples descrição da realidade, mas com a sua construção. Nesta perspectiva, a principal meta do ensino de ciências é procurar demonstrar toda a complexidade do real, pois 
A ciência contemporânea pretende conhecer fenômenos e não coisas. Ela não é de modo algum coisista. A coisa não é mais do que um fenômeno parado. Encontramos-nos então perante uma inversão de complexidade: é preciso conhecer essencialmente os objetos em movimento e procurar em que condições eles podem ser considerados em repouso, fixos no espaço intuitivo; já não se pode, como outrora, conceber os objetos naturalmente em repouso - como coisas - e procurar em que condições eles podem mover-se. (BACHELARD, 1972, p. 154).

Se a ciência não concebe os objetos naturalmente em repouso, então não é possível ensiná-los como se tivessem esse comportamento. Na natureza não existe nenhum fenômeno isolado e imóvel, mas fenômenos que estão interligados entre si e em constante movimento. Assim, não é possível compreender um fenômeno estanque, porque ele não existe na natureza e toda vez que tentarmos compreendê-lo desta maneira, estamos entrando em contradição com a própria realidade. Por isso, o professor, ao realizar o ensino, deve desenvolver uma prática pedagógica que estimule os estudantes a entenderem a realidade desta forma. Não adianta praticar um ensino de ciências que destaque os fenômenos isolados e exigir dos alunos que eles tenham uma concepção de mundo a partir da complexidade da natureza. Logo, toda vez que valorizarmos "o objeto estabilizável, o objeto imóvel, a coisa em repouso formavam o domínio de verificação da lógica aristotélica" (BACHELARD, 1972, p. 155) e não é a concepção aristotélica de ciência que deve ser evidenciada.

Desta forma, o objetivo central do ensino de ciências é promover a superação de uma concepção realista de mundo. Quando o professor valoriza a experiência concreta do aluno e explica os fenômenos do mundo a partir da própria experiência da pessoa, está pensando numa perspectiva realista de ciência, enquanto a ciência moderna pensava um mundo newtoniano, e no momento atual, pelas teorias da relatividade e Mecânica Quântica. O fundamental é promover uma pedagogia que valorize a concepção de ciência que se quer que o estudante compreenda. Se a ciência atual rompeu totalmente com o conhecimento comum, então é conveniente que o seu ensino também rompa com os valores realistas. Por isso, é importante que o professor não ensine numa concepção realista e exija do 
estudante um pensamento na perspectiva newtoniana, por exemplo. É valioso, portanto, desenvolver metodologias que valorizem os aspectos científicos relevantes, através da própria prática pedagógica.

Para tanto, uma ciência de cunho aristotélico não tem valor, porque parte do imediato e este não é o motivador da ciência contemporânea, já que esta não parte dos problemas da realidade imediata, mas de problematizações criadas para serem respondidas por um programa de pesquisa.

Por isso, o conhecimento deve-se processar contra um conhecimento anterior. $\mathrm{Na}$ realidade, toda aquisição de conhecimento deve superar um conhecimento pré-existente, que pode funcionar como obstáculo à aquisição do novo saber. A cristalização de verdades revela-se como impedimentos ao avanço do saber, porque "hábitos intelectuais que foram úteis e sadios podem, com o tempo, entravar a pesquisa" (BACHELARD, 2001, p. 19). Desta forma, não é somente o saber oriundo do senso comum que se constitui em obstáculo, mas o conhecimento científico que existe e que é tomado como verdade definitiva. A crença em uma verdade definitiva não é uma vantagem para o avanço da ciência, porque se torna um grave entrave, por impedir o aparecimento de idéias e conceitos que neguem o saber estabelecido.

O tratamento dado, pelo professor, ao conhecimento existente e prévio dos estudantes deve ser bastante relativizado, para permitir a aquisição dos novos. O professor deve, na realidade, trabalhar a formação de seus alunos de tal modo que os leve a perceberem que não há um conhecimento definitivo e que o saber que eles trazem não se constitui numa verdade pronta e acabada, mas que pode funcionar como barreira à formulações de novos saberes. O educador deve, então, fomentar mecanismos que facilitem a percepção de que a grande qualidade de um sujeito pode ser a capacidade de estar aberto a novas formas de compreender a realidade. O desenvolvimento desta qualidade intrínseca do sujeito é a meta definitiva do processo educativo, isto é, não se tem como objetivo o acúmulo de conteúdos, mas o desenvolvimento de capacidades subjetivas do sujeito, que facilitarão a sua compreensão do fenômeno científico e melhor integração numa sociedade tecnológica.

Assim, a atenção do educador deve voltar-se para o aspecto filosófico do ensino de ciências, onde sua meta principal não será promover um ensino com uma quantidade muito grande de conteúdos, com a finalidade de fazer o estudante 
entender, por exemplo, todo o mundo da Física, que se constitui numa tentativa de fazer o aluno romper com os obstáculos que emperram a compreensão do mundo científico. É conveniente que o educador entenda que "o mundo em que se pensa não é mundo em que se vive" (RIBEIRO FILHO \& VASCONCELOS, 2002, p. 48), mas difere essencialmente.

Por isso, é importante que o professor desenvolva uma série de estratégias que facultem oportunidades de demonstrar que aquele conhecimento que o estudante traz não corresponde a um saber científico e que o próprio conhecimento científico não se constitui numa verdade definitiva. Essas estratégias poderão ser desenvolvidas a partir da História das ciências. A História das ciências permite que o professor encontre exemplos que irão promover, no estudante, o rompimento com o conhecimento imediato e perceber como se deu o avanço do saber científico através de novas descobertas. O estudo da Revolução Científica, por exemplo, faculta ao professor a oportunidade de discutir a ruptura entre a teoria geocêntrica e o surgimento da teoria heliocêntrica. Neste caso, uma teoria embasada na percepção do senso comum, a teoria geocêntrica, e uma teoria formulada a partir de estudos matemáticos mais complexos, a teoria heliocêntrica. $O$ aperfeiçoamento desta teoria, por Kepler, ao prever que as órbitas dos planetas eram elípticas e não circulares, demonstra o avanço da ciência e que o conhecimento adquirido não se constitui numa verdade definitiva. Portanto, a História das ciências é um excelente meio para promover uma mudança conceitual nos estudantes, a partir de exemplos concretos, ocorridos.

A História das ciências faculta, ainda, oportunidades excelentes para trabalharem a superação de muitos obstáculos epistemológicos. Dentre eles, demonstrar que a ciência não pode abarcar com juízos de autoridade. A autoridade é bastante prejudicial ao avanço científico, ao impedir que novas idéias, oriundas de novos cientistas, não sejam aceitas com facilidade. A ciência é fruto de formulações teóricas e provas experimentais que conduzem a novas descobertas. Desta forma, se a autoridade no meio científico não é benéfica, ela é bastante lesiva no meio educacional. Um professor que priorizasse um ensino pela autoridade e não permitesse que houvesse um diálogo entre o mestre e o discípulo, mataria o que se constitui a essência do processo educacional. Um ensino que se caracterizasse pela simples transmissão de um saber cristalizado pela autoridade e não abrisse espaço para o diálogo entre o professor e o aluno, conseqüentemente não poderia 
questionar e propor novas formas de entender os fenômenos estudados. Se a meta do ensino é formar sujeitos, então uma educação transmissora de conteúdos por autoridade do mestre negaria esse princípio e não contribuiria para a formação de sujeitos que interagissem com o processo de aquisição do conhecimento.

O conhecimento científico não pode ser alcançado no isolamento do indivíduo, pois

O homem não está sozinho diante do objeto científico. Não se cultiva mais sozinho. Não nos cultivamos sozinhos. A cultura suscita outro problema além do conhecimento. Incorpora, ao mesmo tempo, uma historicidade que não é a historicidade do sujeito e uma retificação da historicidade de conhecimento do sujeito. A cultura normaliza sua própria história. (BACHELARD, 1977a, p. 160).

Assim, a produção científica se dá com a interação entre os pesquisadores, para validarem um determinado conhecimento. É a comunidade de cientistas que define se uma dada pesquisa tem valor ou não para a ciência. $O$ conhecimento humano é um ato social. Não se pode pensar a produção do conhecimento no isolamento. Bachelard entende que a produção de qualquer saber é possível graças à interação entre os pesquisadores, ao formar uma comunidade que avalia e dá validade ao conhecimento produzido. Portanto,

O conhecimento científico no seu aspecto moderno levando à perfeição toda a sua atualidade, não pode deixar de valorizar-se o seu caráter social bem definido. Conjuntamente, os sábios unem-se numa célula da cidade científica, não apenas para compreenderem, mas ainda para se diversificarem, para ativarem todas as dialéticas que vão dos problemas precisos às soluções originais. A própria diversificação, como deve fazer a prova socialmente do seu valor, não é totalmente individualista. Esta socialização intensa, claramente coerente, segura das suas bases, ardentes nas suas diferenças, é ainda um fato, um fato de uma singular atualidade. Não respeitá-lo seria cair numa utopia gnoseológica, a utopia do individualismo do saber. (BACHELARD, 1990, p. 10).

Nesse sentido, não é admissível aceitar o conhecimento como uma verdade dada e definitiva, mas somente no contexto de uma comunidade científica, 
a cité scientifique, que dá validade ao saber produzido; porque a objetividade científica não é fruto de um método, mas resultado dos critérios adotados por um conjunto de pesquisadores que definem o que é e o que não é ciência. É essa comunidade que define os parâmetros que o pesquisador deve seguir na realização de sua pesquisa.

A produção do conhecimento científico, na perspectiva bachelardiana, pressupõe, acima de tudo, uma interação entre os sujeitos do processo de conhecer porque, "o racionalismo pressupõe a polêmica, o intercâmbio de idéias e a crítica da cidade científica que, num trabalho conjunto de reflexão, consegue instaurar um conhecimento verdadeiramente objetivo" (BARBOSA \& BULCÃO, 2004, p. 58), visto que a verdade não é um conceito a ser conquistado, mas um valor definido por uma comunidade. Esta maneira de encarar a produção do saber é importante, porque todos os envolvidos no processo de conhecer estão imersos num ambiente social. $\mathrm{O}$ cientista está envolvido pela atmosfera da comunidade científica que sua ciência faz parte. Já o estudante, está absorvido pela ambiente social em que vive, que é marcado pelo senso comum. É preciso destacar que a produção científica é afetada por fatores externos que "influenciam o desenvolvimento de uma determinada teoria e como as ciências influenciam as demais áreas de conhecimento, até se embrenhar na vida cotidiana contemporânea por intermédio da tecnologia” (SILVA, 2002, p. 119). É relevante, então, que o professor seja capaz de perceber que o estudante está inserido nesse ambiente social, sendo necessário remover as suas concepções do senso comum, para alcançar a compreensão dos conceitos científicos.

No ambiente escolar existem dois sujeitos que interagem constantemente e que sem eles o processo de ensino-aprendizagem não aconteceria: o professor e o aluno. Estes sujeitos são marcados por toda uma carga de papéis pré-definidos e não é possível pensar uma relação entre eles sem diálogo, onde o professor seja o detentor da verdade e o aluno um mero receptor de conhecimentos. Bachelard propõe uma visão diferente para a relação professor-aluno. Ele sugere que os professores devem estabelecer com seus alunos uma interação dialogada, onde cada parte desempenha seu papel, sem estar presa a ele. Ou seja, professor e aluno têm funções diferentes, mas podem criar um processo interativo onde ocorra uma constante troca de conhecimentos.

Desta forma, o ensino de ciências deve favorecer à construção de um ambiente que estimule a troca de saberes entre o aprendiz e o mestre. A visão 
tradicional, que o professor possui a verdade, não tem espaço na perspectiva bachelardiana, porque o saber não se constitui em definitivo, mas na sua mutabilidade e, portanto, ninguém o detém integral e plenamente. Por isso, o professor deve estar atento ao que acontece em sala de aula, para que possa aproveitar essas experiências para o seu próprio enriquecimento.

$\mathrm{O}$ ato de ensinar possibilita ao professor refletir e avaliar aquilo que sabe. Ao ensinar, o professor consegue perceber se o seu conhecimento tem sentido e se as suas interpretações fazem sentido, porque "a melhor maneira de avaliar a solidez das idéias [é] ensiná-las" (BACHELARD, 1977a, p. 19). A constatação do valor de seu saber se dá porque a sala de aula é um ambiente riquíssimo, por permitir uma troca constante de idéias entre professor e aluno. Por isso é que o professor deve estimular os debates, as pesquisas em sala, para fomentar a descoberta e críticas ao saber estabelecido, porque "o ato de pensar e de reflexão faz parte da própria dinâmica de formação e de educação” (BARBOSA \& BULCÃO, 2004, p. 60).

Essa troca de idéias que Bachelard propõe não deve estar restrita à relação professor-aluno, porque muitas vezes ela é marcada pelo signo da autoridade que impede o diálogo e a interação. Usualmente, o professor utiliza a sua autoridade para dar validade a um determinado conhecimento, sem recorrer ao enfoque científico para validar o seu ensino, porque os educadores

Não conduzem os alunos para o conhecimento do objeto. Emitem mais juízos do que ensinam! Nada fazem para curar a ansiedade que se apodera de qualquer mente diante da necessidade de corrigir sua maneira de pensar e da necessidade de sair de si para encontrar a verdade objetiva. (BACHELARD, 2001, p. 258).

Por esse motivo, Bachelard defende que a interação entre os estudantes é mais rica que a entre professor-aluno, porque não está presa à autoridade do mestre. Sendo assim,

$\mathrm{Na}$ escola, o ambiente jovem é mais formador que o velho; os colegas, mais importantes do que os professores. Os professores, sobretudo na multiplicidade incoerente do ensino secundário, apresentam conhecimentos efêmeros e desordenados, marcados pelo signo nefasto da autoridade. Os alunos assimilam instintos indestrutíveis. Seria preciso incitar os jovens, como grupo, à consciência de uma razão de grupo, ou seja, ao instinto de 
objetividade social, o qual é preterido pelo seu contrário, pelo instinto de originalidade, sem prestar atenção na ilusão dessa originalidade haurida nas disciplinas literárias. Em outros termos, para que a ciência objetiva seja plenamente educadora, é preciso que seu ensino seja socialmente ativo. É um alto desprezo pela instrução o ato de instaurar, sem recíproca, a inflexível relação professor-aluno. A nosso ver, o princípio pedagógico fundamental da atitude objetiva é: Quem é ensinado deve ensinar. Quem recebe instrução e não a transmite terá um espírito formado sem dinamismo nem autocrítica. (BACHELARD, 2001, p. 299-300).

Desta forma, o primordial, no ensino de ciências, é essa interação entre os próprios estudantes, que Ihes possibilita perceber como se dá a produção do conhecimento científico na atualidade, estando habilitados a entender como funciona o mundo da ciência.

Como a função do professor é formar o estudante, ele não deve ensinar apenas o resultado, porque

O ensino dos resultados da ciência nunca é um ensino científico. Se não for explicada a linha de produção espiritual que levou ao resultado, pode-se ter a certeza de que o aluno vai associar o resultado a suas imagens mais conhecidas. É preciso 'que ele compreenda. Só se consegue guardar o que se compreende. O aluno compreende do seu jeito. Já que não lhe deram as razões, ele junta ao resultado razões pessoais'. (BACHELARD, 2001, p. 289).

Por isso, ele não deve substituir

As descobertas por aulas. Contra essa indolência intelectual que nos retira aos poucos o senso da novidade espiritual, o ensino das descobertas ao longo da história científica pode ser de grande ajuda. Para ensinar o aluno a inventar, é bom mostra-lhe que ele pode descobrir. (BACHELARD, 2001, p. 303),

Sendo assim, as estratégias promovidas em sala de aula devem ser direcionadas para uma provocação aos estudantes, através da criação de problemas que sejam solucionados por eles. Ou seja, o professor não deve transmitir o 
conhecimento simplesmente, mas promover meios para que 0 estudante 0 descubra.

Essa perspectiva de ensino exige que o professor trabalhe os conteúdos de ciências a partir da criação de problemas que levem os estudantes à suas resoluções. Logo, a ciência atual "exige, em vez da pausa da dúvida universal, a constituição de uma problemática. Essa procura tem seu ponto de partida real em um problema, mesmo que esse problema seja mal colocado" (BACHELARD, 1977a, p. 63). Neste sentido, não é possível construir o conhecimento a partir da simples exposição de conteúdos, mas partindo de problemáticas formuladas para serem resolvidas pelos estudantes, os quais não mais poderiam se equivocar, quanto ao tratamento que deve ser dado às fórmulas matemáticas, deixando de aprendê-las, apenas, pelo seu ângulo empírico e passível de ser aplicado a cada caso particular, como salienta Bachelard (BACHELARD, 2001, p. 37).

Assim, os problemas utilizados podem ser oriundos da História das ciências ou criados pelo mestre. O fundamental é que haja um problema que force o estudante a procurar respostas. Esse tipo de trabalho propicia a oportunidade do aluno desenvolver habilidades que melhor 0 insira no mundo científico contemporâneo. Como a meta de Bachelard é modificar a constituição interna do sujeito que está em processo de aprendizagem, esta perspectiva permite que o aluno adquira ferramentas para lidar com o mundo e possa compreender como se dá a constituição da ciência atual. Um outro aspecto relevante, desta perspectiva, é que ela está adequada com a visão dos Parâmetros Curriculares Nacionais, quando defende que o fundamental não é o acúmulo de conhecimentos, mas o desenvolvimento de habilidades que facultem ao desenvolvimento de uma cidadania plena, isto é, o importante é que o estudante possa adquirir uma visão crítica e construtiva da ciência e ter uma certa autonomia conceitual acerca dos avanços científicos.

Esse tipo de educação permite que o estudante se forme de tal maneira que consiga entender os mecanismos de construção da ciência contemporânea. Os mecanismos da ciência atual poderiam ser expostos pelo professor, mas isto funcionaria como mera exposição de idéias que não teria o valor da experiência pessoal. É muito mais frutífero, para o estudante, viver o conceito ensinado do que apenas tê-lo aprendido em uma exposição. É através de estratégias desenvolvidas pelo professor que, ao educando, se poderá possibilitar o desenvolvimento das 
habilidades que o façam crescer como ser humano.

Baseado neste ponto de vista, o erro, que é um elemento constituinte do processo de construção do conhecimento, assume uma outra característica no processo de ensino-aprendizagem. Sendo assim, o erro deve ser tratado, no processo de ensino, como algo positivo e que exige uma busca, por parte do estudante, das razões do seu fracasso. Neste aspecto, o erro é o momento onde o professor pode identificar quais das facetas do conteúdo estudados não estão sendo bem compreendidos.

Bachelard entende o erro como o motor do conhecimento. Isso acontece porque o erro é o momento onde uma teoria foi negada em sua realização prática. Sendo assim, é saudável destacar que o fracasso da experiência revela uma área do saber que não foi considerado, pela teoria em vigor.

É importante levar o estudante a compreender que o conhecimento científico é resultado de uma série de erros retificados, ou seja, erros que foram sendo corrigidos com o tempo, no processo de pesquisa. A verdade científica não é definitiva, mas uma construção mutável e que será sempre posta em dúvida por novos conhecimentos. Porque, para Bachelard, "só existe um meio de fazer avançar a ciência; é o de atacar a ciência já constituída, ou seja, mudar a sua constituição" (BACHELARD, 1972, p. 44). Quando formulamos teorias científicas sobre a realidade, não significa que iremos obter um resultado positivo de imediato. Se o erro é tido como positivo para Bachelard, na pesquisa científica, ele deve ser visto como uma metodologia de ensino relevante.

Normalmente, os professores não valorizam os erros dos alunos e entendem que se um estudante erra é porque não aprendeu o conteúdo. Mas esse erro poderia ser utilizado para incentivar a aprendizagem. Esta maneira de tratar o erro deve estar inserida na visão de como se dá a construção do conhecimento científico, pois,

Não existe fracasso radical, mas também não existe êxito definitivo. O pensamento científico, em virtude de seu próprio progresso, está em via de constantes transformações de suas bases, em via de incessantes remanejamentos. (BACHELARD, 1977a, p. 59).

Esta visão do erro deve estar clara para os estudantes, para que eles possam aproveitar toda a riqueza que existe por trás do fracasso momentâneo de 
uma aprendizagem. Eles precisam entender que as grandes teorias que explicam o mundo não foram construídas de uma única vez e que muitos erros e equívocos foram cometidos no processo de construção do saber científico. Este enfoque permite entender que não ocorre um conhecimento definitivo e verdadeiro sobre um determinado fenômeno. O que acontece é um conhecimento aproximado da realidade e que vai sendo aperfeiçoado no decorrer do tempo, com os avanços teóricos e tecnológicos que vão surgindo e permitindo uma melhor compreensão do mundo.

Desta forma, o erro não é a marca dos aprendizes, mas uma realidade que está também naqueles que construíram o saber. "A consciência das dificuldades enfrentadas pelos cientistas na formulação de novos conceitos, pode contribuir para a compreensão de suas próprias dificuldades em aceitá-los" (SILVA, 2002, p. 120). Uma vez de posse desta compreensão, os estudantes, ajudados pelo professor, poderão utilizar o erro como um mecanismo de avanço da aprendizagem, trabalhando aqueles aspectos que não foram compreendidos e buscando solucionar as dificuldades existentes. O erro não deve ser tratado mais como incapacidade do educando, mas como um momento fecundo no processo de ensino-aprendizagem.

Esta forma de tratar a produção do conhecimento científico e a maneira como se dá o processo de ensino-aprendizagem exige uma transformação na concepção de educação por parte do professor, que é o orientador desse processo. Esta transformação é imprescindível, devido o processo educacional demandar muita habilidade e profunda formação na área de ciências e em metodologias, daí a necessidade de uma eficiente formação deste profissional.

Para que o professor ensine, na perspectiva bachelardiana, é importante que ele não esteja contaminado pela visão tradicional de educação. Isto é, um professor que estimule seus alunos a romperem seus obstáculos no aprendizado dos conceitos científicos, e não deva estar impregnado de visões ultrapassadas. Nesse sentido, ele deve ter rompido com os

Primeiros valores; é procura de interesses tão distantes, tão separados dos interesses usuais que se compreende seja tão prontamente desprezado por aqueles que tiram vantagens de engajamentos imediatos e que 'existem' a partir dos valores primeiros, nos valores que lhes são primitivamente dados, seja do exterior, seja do interior. (BACHELARD, 1977a, p. 32). 
O professor precisa sofrer uma catarse psicológica, para mudar as visões que ele tem sobre a formação dos estudantes, para promover um ensino adequado, na perspectiva bachelardiana, já que

A mudança cultural (no caso específico da aquisição da cultura científica) passa por reconhecer que é necessário uma evolução conceitual, de uma concepção realista ingênua, mais próxima do senso comum, para uma concepção racionalista mais avançada, que consiga traduzir o estágio atual do desenvolvimento científico. (LÔBO, 2002, p. 154-155).

Assim, os cursos de formação de professores necessitam enfatizar o aspecto formador da educação e não a assimilação de conteúdos, apenas. Porque o educador deve entender que o processo de ensino-aprendizagem não se resume na repetição de uma aula, mas que é benéfico que o estudante modifique uma concepção que traz do mundo. O professor deve ser capaz de desenvolver estratégias que faculte a oportunidade do aprendiz em romper com os seus conceitos prévios. Estas

Concepções inadequadas de ciência e de conhecimento científico e a sua inserção no espaço escolar, através das aulas de ciências são, em parte, resultantes da ausência de uma abordagem histórica, epistemológica e sociológica da ciência, nos cursos de formação de professores. O que se observa nestes cursos é uma ênfase excessiva sobre os conceitos científicos, em detrimento dos processos de produção da ciência. Desta forma, torna-se necessário repensar o ensino de ciências e a formação do professor buscando inserir os conhecimentos científicos, pedagógico e escolar dentro de referenciais epistemológicos que rompem com a filosofia positivista e sua concepção de verdade científica e mostrem o caráter histórico na produção do conhecimento científico contribuindo, assim, para uma imagem mais adequada da ciência. (LÔBO, 2002, p. 146-147).

Um professor, formado nesta perspectiva, poderia utilizar uma metodologia que rompesse com o modelo tradicional de ensino de ciências. Assim, o ensino de ciências não deveria partir da explicação de conteúdos puros e 
simplesmente, e sim que iniciasse a sua exposição a partir de problemática lançada em classe. Isto é, o professor criaria um problema a ser solucionado na sala de aula pelos alunos. O professor, neste processo, se torna o mediador. Assim, todo o trabalho do professor seria o de conduzir as aulas, no sentido de fornecer subsídios para que os estudantes conseguissem solucionar o problema inicial proposto.

Esta concepção de ensino de ciências é interessante, uma vez que trata o processo de aquisição do conhecimento em sala de aula da mesma forma em que este se dá no meio acadêmico, porque no meio acadêmico o pesquisador é instigado a elaborar uma problemática que sua pesquisa procurará responder. Este tipo de metodologia promoverá, nos estudantes, habilidades de pesquisador, tornando-os aptos a serem futuros pesquisadores e, se não se tornarem pesquisadores, pelo menos saberão como se processa uma pesquisa científica e como é elaborada a ciência contemporânea. 


\section{REFERÊNCIAS}

ASTOLFI, Jean-Pierre \& DEVELAY, Michel. A didática das ciências. 6. ed. Trad. Magda S. S. Fonseca. Campinas: Papirus, 2001.

BACHELARD, Gaston. O novo espírito científico. Trad. Juvenal Hahne Júnior. Rio de Janeiro: Edições Tempo Brasileiro Ltda, 1968.

. Filosofia do novo espírito científico. Trad. Joaquim J. Moura Ramos. Lisboa: Editora Presença, 1972.

. O racionalismo aplicado. Trad. Nathanael C. Caixeiro. Rio de Janeiro: Editora Zahar Editores, 1977a.

. O materialismo racional. Trad. João Gama. Lisboa: Edições

70,1990

A formação do espírito científico: contribuição para uma psicanálise do conhecimento. 3. ed. Trad. Estela dos Santos Abreu. Rio de Janeiro: Contraponto, 2001.

BARBOSA, Elyana. Gaston Bachelard: o arauto da pós-modernidade. 2. ed. Salvador: Editora da Universidade Federal da Bahia, 1996.

BARBOSA, Elyana \& BULCÃO, Marly. Bachelard: pedagogia da razão, pedagogia da imaginação. Petrópolis: Vozes, 2004.

BRASIL. Ministério da Educação. Secretaria de Educação Média e Tecnológica. Parâmetros curriculares nacionais: ensino médio. Brasília: Ministério da Educação, 1999.

LÔBO, Soraia F. Crise no ensino de ciências: um olhar a partir da epistemologia bachelardiana. In: Rev. Ideação - número dedicado a Gaston Bachelard (Núcleo Interdisciplinar de Estudos e Pesquisas em Filosofia), Feira de Santana, n. 9, p. 143157, jan. 2002. 
MATTHEWS, M. R. História, filosofia e ensino de ciências: a tendência atual de reaproximação. Trad. Claudia Mesquita de Andrade. Cadernos Catarinense de Ensino de Física, V 12, n.3: p. 164-214, dez. 1995.

MOREIRA, M. A. Modelos Mentais, Investigações em Ensino de Ciências, 1(3), 1996. Edição eletrônica em http://www.if.ufrgs.br/public/ensino/revista.htm.

MORTIMER, E. F. Construtivismo, mudança conceitual e ensino de ciências: para onde vamos? Investigações em Ensino de Ciências, 1(1), 1996. Edição eletrônica em http://www.if.ufrgs.br/public/ensino/revista.htm

RIBEIRO FILHO, Aurino \& VASCONCELOS, Dionicarlos S. de. Noções fundamentais de mecânica quântica e o livro "philosophie du non" de Gaston Bachelard. In: Rev. Ideação - número dedicado a Gaston Bachelard (Núcleo Interdisciplinar de Estudos e Pesquisas em Filosofia), Feira de Santana, n. 9, p. 3756, jan. 2002.

SILVA, J. L. de Paula Barros. O valor pedagógico da história das ciências. In: Rev. Ideação - número dedicado a Gaston Bachelard (Núcleo Interdisciplinar de Estudos e Pesquisas em Filosofia), Feira de Santana, n. 9, p. 109-124, jan. 2002.

Data de recebimento:08/09/2005

Data de aprovação: 10/04/2006 